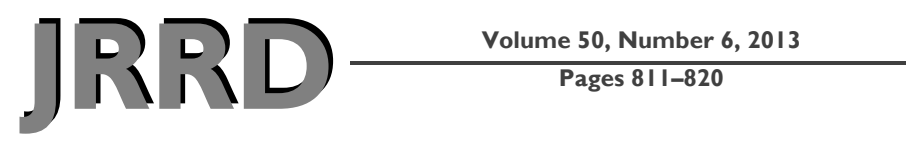

\title{
Chronic physical activity preserves efficiency of proprioception in postural control in older women
}

\author{
Julien Maitre, PhD; ${ }^{1-2}$ Jean-Louis Jully, MD; ${ }^{1}$ Yannick Gasnier, MD; ${ }^{3}$ Thierry Paillard, PhD ${ }^{\mathbf{1}^{*}}$ \\ ${ }^{1}$ Laboratoire Activité Physique, Performance et Santé, EA 4445, Université de Pau et des Pays de l'Adour, \\ Département STAPS, Tarbes, France; ${ }^{2}$ Office Départemental des Sports des Hautes-Pyrénées, Tarbes, France; ${ }^{3}$ Centre \\ Hospitalier de Bigorre, Vic en Bigorre, France
}

\begin{abstract}
The purpose of this study was to compare the effects of proprioceptive disruption on postural control for participants of different ages according to their physical and/or sport activity levels. Two groups of young and old participants who practiced chronic physical and/or sport activities (young active [ $n=17$; average age $20.5+/-1.1 \mathrm{yr}]$ and old active $[n=$ 17 ; average age $74.0+/-3.8 \mathrm{yr}]$ ) and two groups of young and old participants who did not practice physical and/or sport activities (young sedentary [ $n=17$; average age $20.0+/-1.3 \mathrm{yr}]$ and old sedentary $[n=17$; average age $74.7+/-6.3 \mathrm{yr}]$ ) participated in the study. They were compared in a bipedal quiet stance reference condition and a bilateral Achilles tendon vibration condition. Center of foot pressure displacements and frequency analysis were compared between the groups. The results indicated that when proprioceptive information was disrupted, the postural control disturbance was more important for the old sedentary group than for the other groups. There were no differences between the old active group and the young sedentary group. Postural control was less altered for the young active group than for the other groups. Aging decreases the efficiency of postural control regardless of the assessment conditions. Physical and sport activities may compensate for the disturbing effects of proprioceptive perturbation through a better use of sensory information whatever the age of the participants.
\end{abstract}

Key words: aging, balance control, older, physical activity, postural control, proprioception, sensory manipulation, sports, tendon vibration, training.

\section{INTRODUCTION}

Proprioceptive impairment is associated with decreased functional ability and increased fall risk in older individuals [1-2]. Hence, the optimization or preservation of proprioception is crucial in rehabilitation. Indeed, proprioception largely contributes to postural regulation [3]. The contribution of proprioceptive sensory information appears to be reweighted according to environmental constraints and the available sensory information [4]. To quantify the weight of the sensory information in postural regulation, sensory manipulations were used as an experimental probe [4-7]. Brumagne et al. suggested, by means of vibration perturbation, that their older participants increased the weight of the ankle joint proprioception in postural regulation because of a decrease in the sensitivity of paraspinal muscle spindles or changes in the central processing of this afferent information [5]. This may reflect a refocusing of proprioceptive control of balance away from proximal and

Abbreviations: $\mathrm{ANOVA}=$ analysis of variance, $\mathrm{COP}=$ center of foot pressure.

*Address all correspondence to Thierry Paillard, PhD; LAPPS, EA 4445, Université de Pau et des Pays de l'Adour, Département STAPS, ZA Bastillac Sud, 65000 Tarbes, France; 33(0)562566100; fax: 33(0)562566110.

Email: thierry.paillard@univ-pau.fr http://dx.doi.org/10.1682/JRRD.2012.08.0141 
axial proprioception input to that derived from receptors in the ankle muscles [5]. Indeed, the involutions of the visual system [8-9], the vestibular system [10], the proprioceptive system $[1,11]$ and the central processing mechanisms [12-14] induced by aging contribute to affect the dynamic regulation of the sensorimotor integration and decrease the efficiency of postural regulation [15].

However, regular and chronic physical activity is known to play a fundamental role in the improvement and preservation of balance ability in older participants [1617] by repetitive stimulations of the sensorimotor systems. Furthermore, chronic sport activities can also improve postural regulation for young participants $[6,18]$. Thus, young and older individuals who practice chronic physical and/or sport activities likely demonstrate more efficient postural ability to withstand proprioceptive disturbance than other same-age individuals who do not practice physical and/or sport activities.

Hence, the main objectives of this study were to (1) emphasize the contribution of ankle proprioception on postural regulation according to the age and the physical and/or sport activity status of the participants and (2) clarify the resultant between the benefits induced by the chronic practice of physical activity and the involutions induced by aging on the postural regulation. Since aging and chronic physical activity have opposite effects on postural regulation, we hypothesized that the benefits induced by the chronic practice of physical activity may compensate for the involutions related to aging on postural ability to withstand challenging conditions, such as proprioceptive disruption. Moreover, some studies have reported differences between men and women in postural regulation [19-22]. Hence, to exclude the influence of an eventual sex effect, we have voluntarily chosen to focus only on women in this study.

\section{METHODS}

\section{Participants}

Sixty-eight healthy women shown to be free from any neurological, motor, or metabolic disorders after medical examination participated in the study. They were divided into four groups. Thirty-four young participants were divided into two groups: seventeen sporting participants (young active group) and seventeen nonsporting participants (young sedentary group). Thirty-four old participants were also divided into two groups: seventeen active participants (old active group) and seventeen nonactive participants (old sedentary group). Age and anthropometric data are presented in Table 1. After interviewing each subject, we included in the young active group persons who practiced sports in competition (e.g., swimming, gymnastics, handball, basketball, athletics) at at least a regional level and who trained three times a week ( $3 \mathrm{~h}$ or more a week) in addition to physical and/or sport activities practiced at college. We included in the young sedentary group persons who had not practiced physical and/or sport activities for at least $3 \mathrm{yr}$, except at college (less than $2 \mathrm{~h}$ a week). We included in the old active group persons who had regularly practiced physical activity (3 h or more a week) in a sports club (e.g., gymnastics, walking, dancing, aquarobics) for at least $3 \mathrm{yr}$. We included in the old sedentary group persons who had not practiced physical activity (at home or in a sports club) for at least 3 yr except for daily tasks. All the participants led independent lives. Exclusion criteria included a documented postural system disorder or a medical condition that might affect postural regulation, a neurological or a musculoskeletal impairment, or a current injury that made the participants unable to participate. We excluded persons who were not able to walk without a

Table 1.

Mean \pm standard deviation age and anthropometric data for four study groups.

\begin{tabular}{lccccc}
\hline \multirow{2}{*}{ Characteristic } & \multicolumn{2}{c}{ Group } & \multicolumn{2}{c}{ F and $\boldsymbol{p}$-Value } \\
\cline { 2 - 5 } & Young Active & Young Sedentary & Old Active & Old Sedentary & \\
\hline Age $(\mathrm{yr})$ & $20.5 \pm 1.1$ & $20.0 \pm 1.3$ & $74.0 \pm 3.8^{* \dagger}$ & $74.7 \pm 6.3^{* \dagger}$ & $F=1158.7, p<0.001$ \\
Height $(\mathrm{cm})$ & $164.8 \pm 5.7$ & $162.3 \pm 5.4$ & $156.6 \pm 4.2^{* \dagger}$ & $155.8 \pm 5.7^{* \dagger}$ & $F=11.8, p<0.001$ \\
Weight $(\mathrm{kg})$ & $60.5 \pm 7.1$ & $56.2 \pm 9.2$ & $63.2 \pm 6.9$ & $62.4 \pm 9.0$ & - \\
Foot Size $(\mathrm{cm})$ & $26.0 \pm 0.9$ & $25.5 \pm 0.8$ & $25.6 \pm 0.8$ & $25.3 \pm 0.7$ & - \\
\hline
\end{tabular}

Note: Significant differences are included at level of 5 percent.

* Post hoc analysis difference from young active group.

${ }^{\dagger}$ Post hoc analysis difference from young sedentary group. 
walking stick and who were in a nursing home. Concerning the medical examination criteria, we excluded persons in the following categories: those who had experienced hip, knee, or ankle traumas in the past $2 \mathrm{yr}$; lesion of the foot skin support surface; or ankylosis of a large lowerlimb joint (hip, knee, ankle); those who had disabling low vision despite correction or experienced chronic respiratory insufficiency requiring treatment with oxygen therapy; those undergoing medical treatment (bronchodilators, beta-blockers, corticosteroid, neuroleptics); and those with cardiovascular disease (coronary artery disease, myocardial infarction, congestive heart failure, permanent or paroxysmal heart rhythm disturbances, poorly controlled hypertension); neurological deficit; or disorders of higher functions, tone, sensitivity, and balance. We excluded from the young participant groups persons who were not taking contraceptive medication or who were pregnant.

\section{Measurements}

Participants were instructed to stand barefoot as motionless as possible on a force platform with three strain gauges ( $40 \mathrm{~Hz}$ frequency, 12 bit $\mathrm{A} / \mathrm{D}$ conversion, Techno Concept; Cereste, France). They kept their arms next to their body, with their eyes fixed on a target $\left(4 \mathrm{~cm}^{2}\right)$ $1.5 \mathrm{~m}$ in front of them at eye level. Their legs were straight and their feet formed a $30^{\circ}$ angle relative to each other according to precise marks (intermalleolar distance of $9 \mathrm{~cm}$ ).

They were tested in two conditions: a reference condition (i.e., quiet stance) and a sensory-manipulation condition. The main objective of this sensory-manipulation condition was to alter the proprioceptive information by means of tendinous vibratory stimuli, which modulate Ia afferences [23-24]. The tendon vibration was applied to the Achilles tendons of both legs (tendon vibration condition) by means of two inertial vibrators (VB 115, Techno Concept) secured with elastic bands. Vibration frequency was set at $40 \mathrm{~Hz}$ and the amplitude was $0.85 \mathrm{~mm}$. Each condition lasted $20 \mathrm{~s}$ and the participants kept their eyes open. To avoid initial transients and anticipation behavior recording at the onset of the sensory disturbance, the sensory manipulation was set up in a range of $5 \mathrm{~s}$ before the recording of postural sway data.

POSTUROWIN software (Techno Concept) recorded the center of foot pressure (COP) displacement parameters that characterize the postural behavior. The COP surface (in millimeters squared) is an indicator of the subject's postural stability [25]; the smaller the COP surface area, the better the stability. The COP velocity is an indicator of the subject's postural control [25]; the smaller the COP velocity, the better the postural control. The COP velocity can be detailed on the mediolateral axis in $\mathrm{COP}_{X}$ velocity (in millimeters per second) and on the anterior-posterior axis in $\mathrm{COP}_{y}$ velocity (in millimeters per second).

PosturoPro ${ }^{\circledR}$ software (Framiral; Cannes, France) analyzed stabilometric data to characterize spectral power density of the COP displacements by the wavelet transform. Application of the wavelet transform method to COP displacements provides a time-frequency chart of body sway and a three-dimensional representation of body sway [26-27]. The spectral analysis was computed for three frequency bands defined on the $x$-axis (frontal plane) and the $y$-axis (sagittal plane) as follows: $0.05-0.5 \mathrm{~Hz}$ (low frequencies $\mathrm{LF}_{X}$ and $\mathrm{LF}_{y}$ ), $0.5-1.5 \mathrm{~Hz}$ (medium frequencies $\mathrm{MF}_{x}$ and $\mathrm{MF}_{y}$ ), and 1.5-10 $\mathrm{Hz}$ (high frequencies $\mathrm{HF}_{x}$ and $\mathrm{HF}_{y}$ ), expressed in arbitrary units [28]. This analysis characterizes the postural strategy used by the subjects. The low and medium frequencies are in domains mostly related to the visual and vestibular/somatosensory contribution to postural regulation, respectively [29-30]. As a rule, power in the higher band is not present in healthy subjects during quiet standing, but it can be seen with aging.

\section{Statistical Analysis}

Statistical analyses were performed with Statistica software (StatSoft Inc; Tulsa, Oklahoma). One-factor analysis of variance (ANOVA) was performed to determine whether there were differences among the four groups regarding age, anthropometric data, and COP displacements and spectral power density parameters in the reference condition. The effects of condition (reference and tendon vibration), age (young and old), and activity (active and sedentary) were tested using three-factor ANOVA with repeated measures on three factors. When a significant treatment effect occurred, Newman-Keuls post hoc analyses were used to test the difference among means. Results were considered significant at the level of 5 percent.

\section{RESULTS}

\section{Age and Anthropometric Data}

Results concerning age and anthropometric data are presented in Table 1. The results indicated, obviously, significant age differences between the young and old 
participants. Furthermore, the young participant groups were taller than the old participant groups.

\section{Reference Condition Comparisons Between Groups}

Results concerning the reference condition comparisons among the four groups are presented in Table 2. Concerning COP displacements, the results showed that the COP surface and the $\mathrm{COP}_{y}$ velocity differed significantly among the four groups. The post hoc analyses indicated that $\mathrm{COP}_{y}$ velocity was higher for the old sedentary group than for the young sedentary and young active groups. Furthermore, the $\mathrm{COP}_{y}$ velocity was higher for the old active group than for the young sedentary and young active groups. The COP surface was lower for the young active group than for the old sedentary and old active groups.

As regards the spectral power density, $\mathrm{LF}_{x}, \mathrm{LF}_{y}, \mathrm{MF}_{y}$ and $\mathrm{HF}_{y}$ differed significantly among the four groups. The post hoc analyses indicated that the spectral power density was higher for the old sedentary group than for the young sedentary group $\left(\mathrm{MF}_{y}, \mathrm{HF}_{y}\right)$ and the young active group $\left(\mathrm{LF}_{x}, \mathrm{LF}_{y}, \mathrm{MF}_{y} \mathrm{HF}_{y}\right)$. It was also higher for the old active group than for the young sedentary group $\left(\mathrm{LF}_{x}, \mathrm{MF}_{y}, \mathrm{HF}_{y}\right)$ and the young active group $\left(\mathrm{LF}_{x}, \mathrm{LF}_{y}\right.$ $\mathrm{MF}_{y}, \mathrm{HF}_{y}$ ).

\section{Evolution of Center of Foot Pressure Displacements}

Results concerning the evolution of the COP parameters are presented in Table 3. As regards the COP displacements, COP surface, $\mathrm{COP}_{x}$ velocity, and $\mathrm{COP}_{y}$ velocity presented a significant condition effect, indicating that the tendon vibration condition altered postural behavior for all the groups.

The COP surface and the $\mathrm{COP}_{y}$ velocity presented a significant condition $\times$ age interaction, indicating that the vibration effects on postural behavior were altered according to age. The postural behavior was more disturbed for the older participants than for the younger participants in the tendon vibration condition.

The COP surface, the $\mathrm{COP}_{x}$ velocity, and the $\mathrm{COP}_{y}$ velocity presented a significant condition $\times$ activity interaction, indicating that the vibration effects on postural behavior were altered according to the physical and/or sport activity status of the groups. Postural behavior was more disturbed for the sedentary participants than for the active participants in the tendon vibration condition.

The COP surface and the $\mathrm{COP}_{y}$ velocity presented a significant condition $\times$ age $\times$ activity interaction, indicating that the vibration effects on postural behavior were altered according to age and the physical and/or sport activity status of the groups.

The post hoc analyses revealed that most COP displacements increased more for the old sedentary group

Table 2.

Center of foot pressure (COP) parameters (mean \pm standard deviation [SD]) and spectral power density (mean \pm SD) in three frequency bands (on $x$ - and $y$-axes) for four study groups in reference condition (i.e., quiet stance).

\begin{tabular}{|c|c|c|c|c|c|}
\hline \multirow{2}{*}{ Parameter } & \multicolumn{4}{|c|}{ Group } & \multirow{2}{*}{$F$ and $p$-Value } \\
\hline & Young Active & Young Sedentary & Old Active & Old Sedentary & \\
\hline \multicolumn{6}{|l|}{ Postural } \\
\hline COP Surface & $41.8 \pm 18.8$ & $60.9 \pm 34.8$ & $96.7 \pm 45.3^{*}$ & $91.9 \pm 80.6^{*}$ & $F=4.6, p<0.01$ \\
\hline $\mathrm{COP}_{X}$ Velocity & $3.9 \pm 0.8$ & $4.4 \pm 1.0$ & $4.5 \pm 1.4$ & $4.0 \pm 1.2$ & - \\
\hline $\mathrm{COP}_{y}$ Velocity & $4.5 \pm 1.0$ & $5.0 \pm 1.1$ & $6.9 \pm 2.4^{* \dagger}$ & $7.5 \pm 2.7^{* \dagger}$ & $F=9.3, p<0.001$ \\
\hline \multicolumn{6}{|c|}{ Spectral Power Density } \\
\hline $\mathrm{LF}_{X}$ & $52.8 \pm 4.2$ & $54.6 \pm 6.8$ & $60.1 \pm 5.6^{* \dagger}$ & $57.9 \pm 6.7^{*}$ & $F=5.2, p<0.01$ \\
\hline $\mathrm{LF}_{y}$ & $58.4 \pm 4.2$ & $61.0 \pm 5.6$ & $64.5 \pm 5.0^{*}$ & $64.6 \pm 6.3^{*}$ & $F=5.3, p<0.01$ \\
\hline $\mathrm{MF}_{X}$ & $44.5 \pm 4.1$ & $46.3 \pm 5.3$ & $49.1 \pm 5.6$ & $46.1 \pm 6.4$ & - \\
\hline $\mathrm{MF}_{y}$ & $47.3 \pm 4.4$ & $49.6 \pm 4.6$ & $55.1 \pm 5.2^{* \dagger}$ & $54.7 \pm 6.0^{* \dagger}$ & $F=9.8, p<0.001$ \\
\hline $\mathrm{HF}_{X}$ & $25.3 \pm 4.8$ & $27.8 \pm 5.5$ & $29.7 \pm 5.7$ & $27.8 \pm 6.3$ & - \\
\hline$\hat{\mathrm{HF}_{y}}$ & $31.1 \pm 3.8$ & $32.3 \pm 4.4$ & $37.7 \pm 6.0^{* \dagger}$ & $38.1 \pm 6.9^{* \dagger}$ & $F=7.5, p<0.001$ \\
\hline $\begin{array}{l}\text { Note: Significant differ } \\
{ }^{*} \text { Post hoc analysis diffe } \\
{ }^{\top} \text { Post hoc analysis diffe } \\
\text { HF = high frequency, L }\end{array}$ & $\begin{array}{l}\mathrm{d} \text { at level of } 5 \text { per } \\
\text { pung active group } \\
\text { bung sedentary gr } \\
\text { ency, MF = medi }\end{array}$ & quency. & & & \\
\hline
\end{tabular}


Table 3.

Center of foot pressure (COP) parameters (mean \pm standard deviation) for four study groups in reference (REF) and Achilles tendon vibration (TV) conditions.

\begin{tabular}{|c|c|c|c|c|c|c|c|c|c|}
\hline \multirow[b]{2}{*}{$\begin{array}{c}\text { Postural } \\
\text { Parameter }\end{array}$} & \multirow[b]{2}{*}{ Condition } & \multicolumn{4}{|c|}{ Group } & \multicolumn{4}{|c|}{$F$ and $p$-Value } \\
\hline & & $\begin{array}{l}\text { Young } \\
\text { Active }\end{array}$ & $\begin{array}{c}\text { Young } \\
\text { Sedentary }\end{array}$ & $\begin{array}{c}\text { Old } \\
\text { Active }\end{array}$ & $\begin{array}{c}\text { Old } \\
\text { Sedentary }\end{array}$ & Condition & $\begin{array}{c}\text { Condition } \times \\
\text { Age }\end{array}$ & $\begin{array}{c}\text { Condition } \times \\
\text { Activity }\end{array}$ & $\begin{array}{c}\text { Condition } \times \\
\text { Age } \times \\
\text { Activity }\end{array}$ \\
\hline \multirow[t]{2}{*}{ COP Surface } & REF & $41.8 \pm 18.8$ & $60.9 \pm 34.8$ & $96.7 \pm 45.3$ & $91.9 \pm 80.6$ & $F=81.3$ & $F=6.2$, & $F=16.5$ & $F=7.3$ \\
\hline & TV & $126.8 \pm 69.5$ & $190.7 \pm 106.6$ & $174.7 \pm 66.7$ & $393.1 \pm 247.8^{* \dagger \ddagger}$ & $p<0.001$ & $p<0.05$ & $p<0.001$ & $p<0.01$ \\
\hline \multirow[t]{2}{*}{$\mathrm{COP}_{X}$ Velocity } & REF & $3.9 \pm 0.8$ & $4.4 \pm 1.0$ & $4.5 \pm 1.4$ & $4.0 \pm 1.2$ & $F=355.1$ & & $F=8.2$ & \\
\hline & TV & $8.7 \pm 1.7$ & $9.6 \pm 1.5$ & $8.9 \pm 2.2$ & $11.2 \pm 4.2^{* \ddagger}$ & $p<0.001$ & & $p<0.01$ & \\
\hline \multirow[t]{2}{*}{$\mathrm{COP}_{y}$ Velocity } & REF & $4.5 \pm 1.0$ & $5.0 \pm 1.1$ & $6.9 \pm 2.4$ & $7.5 \pm 2.7$ & $F=158.9$ & $F=21.5$ & $F=5.2$ & $F=5.5$ \\
\hline & TV & $8.7 \pm 2.1$ & $11.2 \pm 3.9$ & $14.1 \pm 4.6^{*}$ & $23.0 \pm 11.0^{* \dagger \ddagger}$ & $p<0.001$ & $p<0.001$ & $p<0.001$ & $p<0.05$ \\
\hline \multicolumn{10}{|c|}{$\begin{array}{l}\text { Note: Significant differences included at level of } 5 \text { percent. } \\
{ }^{*} \text { Post hoc analysis difference from young active group. } \\
{ }^{\dagger} \text { Post hoc analysis difference from young sedentary group. } \\
{ }^{\ddagger} \text { Post hoc analysis difference from old active group. }\end{array}$} \\
\hline
\end{tabular}

than for the old active group (COP surface, $\mathrm{COP}_{x}$ velocity, $\mathrm{COP}_{y}$ velocity), young sedentary group (COP surface, $\mathrm{COP}_{y}$ velocity), and young active group (COP surface, $\mathrm{COP}_{x}$ velocity, $\mathrm{COP}_{y}$ velocity). In addition, $\mathrm{COP}_{y}$ velocity was lower for the young active group than for the old active group.

\section{Evolution of Spectral Power Density Parameters}

Results concerning the evolution of spectral power density in the three frequency bands are presented in Table 4. As regards the spectral power density parameters, $\mathrm{LF}_{X}$, $\mathrm{LF}_{y}, \mathrm{MF}_{x}, \mathrm{MF}_{y} \mathrm{HF}_{x}$, and $\mathrm{HF}_{y}$ presented a significant condition effect, indicating that the tendon vibration condition altered postural strategy for all the groups.

$\mathrm{LF}_{x}, \mathrm{MF}_{x}, \mathrm{MF}_{y}, \mathrm{HF}_{x}$, and $\mathrm{HF}_{y}$ presented a significant condition $\times$ activity interaction, indicating that the vibration effects on postural strategy were altered according to the physical and/or sport activity status of the groups. The postural strategy was more altered for the sedentary participants than for the active participants in the tendon vibration condition.

$\mathrm{LF}_{X}, \mathrm{MF}_{X}$, and $\mathrm{HF}_{X}$ presented a significant condition $\times$ age $\times$ activity interaction, indicating that the vibration effects on postural strategy were altered according to the age and the physical and/or sport activity status of the groups.

The post hoc analyses indicated that the spectral power density increased more for the old sedentary group than for the old active group $\left(\mathrm{LF}_{x}, \mathrm{MF}_{x}, \mathrm{MF}_{y} \mathrm{HF}_{x}, \mathrm{HF}_{y}\right)$ and the young active group $\left(\mathrm{LF}_{x}, \mathrm{MF}_{y}, \mathrm{HF}_{x}, \mathrm{HF}_{y}\right)$. In addition, spectral power density increased less for the young active group than for the young sedentary group $\left(\mathrm{MF}_{y}, \mathrm{HF}_{y}\right)$.

\section{DISCUSSION}

The main results indicated that aging disturbed postural behavior in the reference and tendon vibration conditions. However, this disturbance was limited by the chronic practice of physical and/or sport activities in the condition where proprioception was disturbed for the old active group and the young active group. The chronic practice of physical and/or sport activities has positive effects on postural regulation efficiency, whatever the age of the participants. These effects render the old active group as efficient as the young sedentary group at withstanding proprioceptive disruption.

Postural behavior in the reference condition corroborates previous studies [31-32] that indicated that older groups were less stable than young groups, particularly in the anteroposterior direction. The involution of the sensory systems, central processing system, and motor output that occurs with aging constitutes the main factor altering postural regulation efficiency [14-15].

When proprioceptive information was altered (tendon vibration condition), postural behavior was disturbed for each group. Moreover, the postural behavior disturbance was more important for the old sedentary group than for the three other groups. There was no difference between the old active group and the young sedentary group when proprioceptive information was disrupted. The outcomes showed that the postural disturbance was less important for the young active group than for not only the old sedentary and old active groups but also the young sedentary group. These results indicate not only that aging decreases the efficiency of postural regulation to withstand proprioceptive 
JRRD, Volume 50, Number 6, 2013

Table 4.

Spectral power density (mean \pm standard deviation) in three frequency bands (on $x$ - and $y$-axes) for four study groups in reference (REF) and Achilles tendon vibration (TV) conditions.

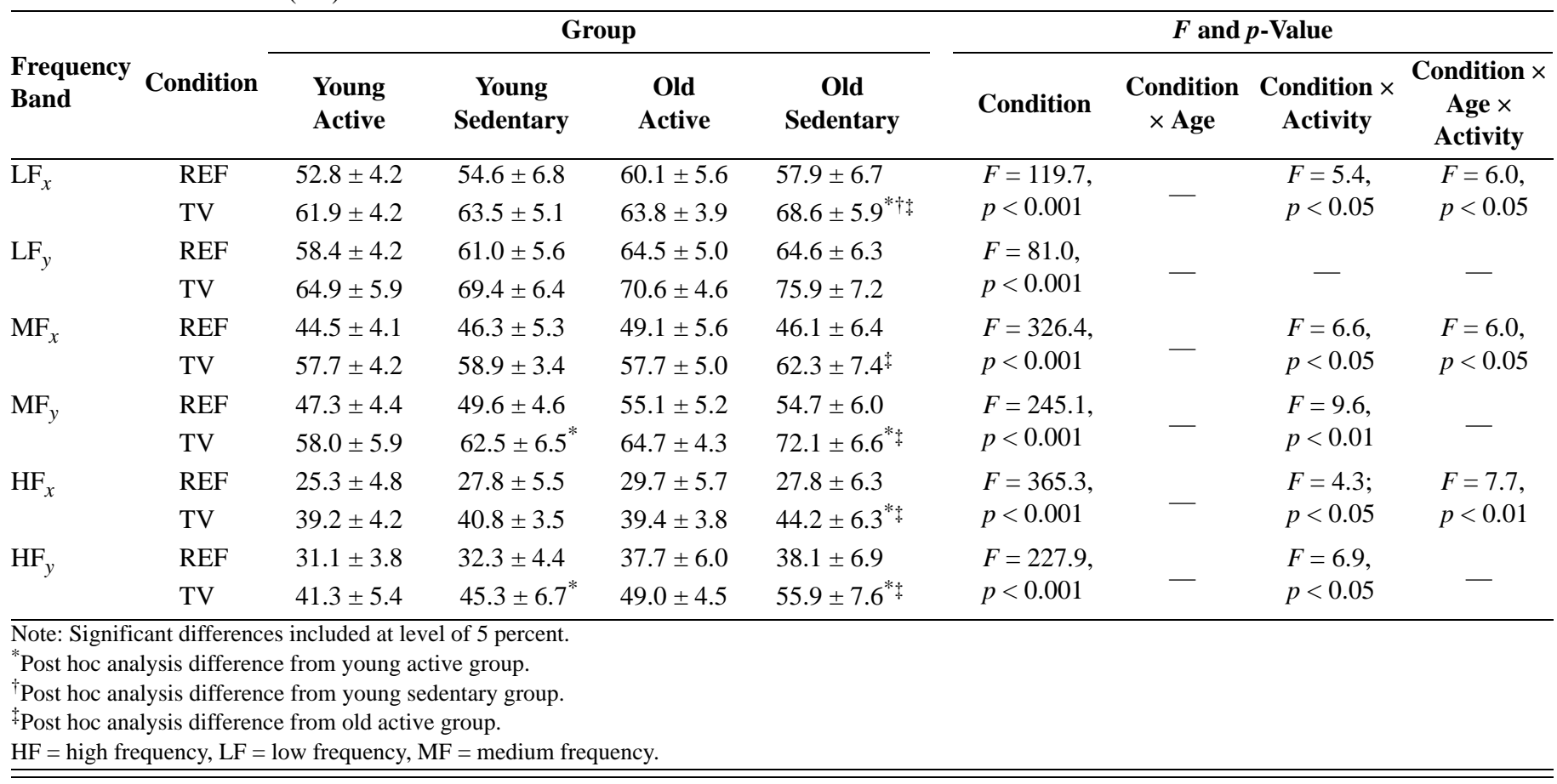

perturbation, but also that physical and sport activities may compensate for the disturbing effects related to age on the postural ability to withstand challenging conditions. The proprioceptive contribution in postural regulation or the ability to use other sensory inputs to withstand the sensory manipulation appeared to differ between the four groups.

In the present study, the older groups responded to vibration stimulation, demonstrating that the proprioceptive system was still effective. The vibration effects on postural behavior with aging are not uniform. Previous studies observed that the intensity of the postural response to vibration decreased and construed that this was due to a central level decline of the postural regulation system (in participants aged 60 to 86) [33] or an alteration of the stretch reflex (in participants aged older than 85) [34]. Conversely, Brumagne et al. observed that their older participants (mean age 63) were as sensitive as their young participants to vibration stimulation and suggested that the older age of participants in these previous studies could explain the weaker effects of the vibration stimulation [5]. The postural response to vibration stimulation is a complex multisegment synergy [35] that differs depending on the individual's age [36]. This response may be modulated by the integrity of and the ability to use other sensory afferences (i.e., visual, vestibular, and cutaneous) [37-38]. In fact, the weight of proprioceptive contribution to spatial orientation [39] and postural regulation [5] may change according to the integrity of peripheral sensory systems. Brumagne et al. suggested that a refocusing of proprioceptive control of balance away from proximal and axial proprioception input to that derived from receptors in the ankle muscles would occur [5]. Hence, the contribution of ankle proprioception to postural regulation could be solicited more for the old sedentary group than for the three other groups for a simple task like maintaining quiet stance. This means that when proprioception was disrupted, the old sedentary group using proprioception in a dominating way might have saturated the proprioceptive system more quickly and was unable to compensate further postural disturbances compared with the other groups.

Nevertheless, postural behavior was significantly less disturbed by the proprioceptive disruption for the old active group than for the old sedentary group. Chronic physical activity involves repetitive stimulations of sensory systems that are known to enhance the efficiency, or at least limit the involution of, different neural loops involved in postural regulation induced by aging 
[16,29,40-44]. Similarly, the postural disturbance was less important for the young active group than for the three other groups, which highlights that chronic practice of sports is also positive for the postural regulation of young individuals [6,45-47]. These studies suggested that physical and sport activities might improve the ability to withstand postural disturbance through a better use of the sensory information, whatever the age of the participants. When proprioception was disrupted, all the participant groups might have been compelled to rely more on other sensory inputs (e.g., visual and vestibular) to maintain postural stability. Since the old sedentary group did not benefit from the effects of physical activity, it would not have been able to compensate for the proprioceptive disruption by the use of the nondisrupted sensory inputs as efficiently as the three other groups. Conversely, chronic physical activity is likely to preserve the ability to reweight inaccurate proprioceptive information because no difference was found between the old active group and the young sedentary group in the tendon vibration condition. Physical activity may counteract aging's effect on the postural ability to withstand proprioceptive disruption. Moreover, chronic practice of sport activities resulted in a more efficient postural regulation for the young active group compared with the three other groups. The young active group probably used the nondisrupted sensory inputs to limit the postural disturbance more efficiently than the three other groups.

\section{CONCLUSIONS}

In conclusion, there is no doubt that aging decreases postural regulation ability in women. Although the efficiency of proprioception diminishes with age, the contribution of ankle proprioception to postural regulation might be solicited more for the old sedentary group than for the three other groups for a simple task like maintaining quiet stance. When proprioceptive information was disturbed by means of Achilles tendon vibration, the old sedentary group saturated proprioception more quickly than the three other groups. Furthermore, the old active group preserved the ability to withstand postural disturbance at the same level as the young sedentary group. Older women should regularly practice physical activities that particularly stimulate proprioception to preserve postural regulation efficiency. It would be interesting to determine the extent to which each physical activity influences the ability to withstand proprio- ceptive disruption in female subjects. Physical therapists could thereby propose a physical activity adapted to the rehabilitation of the proprioception.

\section{ACKNOWLEDGMENTS}

\section{Author Contributions:}

Concept and design: J. Maitre, T. Paillard, J. L. Jully, Y. Gasnier. Acquisition of data: J. Maitre, T. Paillard, J. L. Jully, Y. Gasnier. Analysis and interpretation of data: J. Maitre, T. Paillard. Preparation of manuscript: J. Maitre, T. Paillard.

Medical examination of participants: J. L. Jully, Y. Gasnier.

Financial Disclosures: The authors have declared that no competing interests exist.

Funding/Support: This material was based on work supported by grants from Association Nationale de la Recherche et de la Technologie and Conseil Général des Hautes Pyrénées. The sponsors had no role in the design, methods, participant recruitment, data collections, analysis, or preparation of the manuscript.

Additional Contributions: The authors thank all the participants for their helpful cooperation.

Institutional Review: This experimental procedure received the approval of the local committee for the protection of human subjects, and all participants gave informed consent.

Participant Follow-Up: The authors plan to inform participants of the publication of this study.

\section{REFERENCES}

1. Goble DJ, Coxon JP, Wenderoth N, Van Impe A, Swinnen SP. Proprioceptive sensibility in the elderly: degeneration, functional consequences and plastic-adaptive processes. Neurosci Biobehav Rev. 2009;33(3):271-78. [PMID:18793668] http://dx.doi.org/10.1016/j.neubiorev.2008.08.012

2. Lord SR, Sturnieks DL. The physiology of falling: assessment and prevention strategies for older people. J Sci Med Sport. 2005;8(1):35-42. [PMID:15887899] http://dx.doi.org/10.1016/S1440-2440(05)80022-2

3. Simoneau GG, Ulbrecht JS, Derr JA, Cavanagh PR. Role of somatosensory input in the control of human posture. Gait Posture. 1995;3:115-22.

http://dx.doi.org/10.1016/0966-6362(95)99061-O

4. Peterka RJ. Sensorimotor integration in human postural control. J Neurophysiol. 2002;88(3):1097-1118. [PMID:12205132]

5. Brumagne S, Cordo P, Verschueren S. Proprioceptive weighting changes in persons with low back pain and elderly persons during upright standing. Neurosci Lett. 2004;366(1):63-66. [PMID:15265591] http://dx.doi.org/10.1016/j.neulet.2004.05.013 
6. Paillard T, Bizid R, Dupui P. Do sensorial manipulations affect subjects differently depending on their postural abilities? Br J Sports Med. 2007;41(7):435-38.

[PMID:17311808]

http://dx.doi.org/10.1136/bjsm.2006.032904

7. Horak FB, Hlavacka F. Somatosensory loss increases vestibulospinal sensitivity. J Neurophysiol. 2001;86(2):575-85. [PMID:11495933]

8. Owsley C. Aging and vision. Vision Res. 2011;51(13): 1610-22. [PMID:20974168] http://dx.doi.org/10.1016/j.visres.2010.10.020

9. Salvi SM, Akhtar S, Currie Z. Ageing changes in the eye. Postgrad Med J. 2006;82(971):581-87. [PMID:16954455] http://dx.doi.org/10.1136/pgmj.2005.040857

10. Sloane PD, Baloh RW, Honrubia V. The vestibular system in the elderly: clinical implications. Am J Otolaryngol. 1989;10(6):422-29. [PMID:2688446] http://dx.doi.org/10.1016/0196-0709(89)90038-0

11. Shaffer SW, Harrison AL. Aging of the somatosensory system: a translational perspective. Phys Ther. 2007;87(2): 193-207. [PMID:17244695] http://dx.doi.org/10.2522/ptj.20060083

12. Teasdale N, Stelmach GE, Breunig A, Meeuwsen HJ. Age differences in visual sensory integration. Exp Brain Res. 1991;85(3):691-96. [PMID:1915717] http://dx.doi.org/10.1007/BF00231755

13. Hay L, Bard C, Fleury M, Teasdale N. Availability of visual and proprioceptive afferent messages and postural control in elderly adults. Exp Brain Res. 1996;108(1):129-39. [PMID:8721161] http://dx.doi.org/10.1007/BF00242910

14. Woollacott MH. Systems contributing to balance disorders in older adults. J Geront A Biol Sci Med Sci. 2000;55: M424-28.

15. Sturnieks DL, St George R, Lord SR. Balance disorders in the elderly. Neurophysiol Clin. 2008;38(6):467-78. [PMID:19026966] http://dx.doi.org/10.1016/j.neucli.2008.09.001

16. Perrin PP, Gauchard GC, Perrot C, Jeandel C. Effects of physical and sporting activities on balance control in elderly people. Br J Sports Med. 1999;33(2):121-26. [PMID:10205695] http://dx.doi.org/10.1136/bjsm.33.2.121

17. Howe TE, Rochester L, Jackson A, Banks PM, Blair VA. Exercise for improving balance in older people. Cochrane Database Syst Rev. 2007;(4):CD004963.

18. Hrysomallis C. Balance ability and athletic performance. Sports Med. 2011;41(3):221-32. [PMID:21395364] http://dx.doi.org/10.2165/11538560-000000000-00000

19. Kim J, Kwon Y, Eom G-M, Jun J-H, Lee J-W, Tack G-R. Effects of vision, age and gender on structural and global posturographic features during quiet standing. Int J Precis
Eng Manuf. 2012;13:969-75.

http://dx.doi.org/10.1007/s12541-012-0126-Z

20. Kim J, Kwon Y, Kim J, Chung HY, Park S, Kim CS, Eom GM, Jun JH, Park B, An H, Ryu JC. Gender-differences in the associations of anthropometry with postural sway in feet-together stance. Int J Precis Eng Manuf. 2012;13: 1897-1902. http://dx.doi.org/10.1007/s12541-012-0249-2

21. Kim JW, Eom GM, Kim CS, Kim DH, Lee JH, Park BK, Hong J. Sex differences in the postural sway characteristics of young and elderly subjects during quiet natural standing. Geriatr Gerontol Int. 2010;10(2):191-98. [PMID:20100287]

22. Era P, Sainio P, Koskinen S, Haavisto P, Vaara M, Aromaa A. Postural balance in a random sample of 7,979 subjects aged 30 years and over. Gerontology. 2006;52(4):204-13. [PMID:16849863] http://dx.doi.org/10.1159/000093652

23. Roll JP, Vedel JP. Kinaesthetic role of muscle afferents in man, studied by tendon vibration and microneurography. Exp Brain Res. 1982;47(2):177-90. [PMID:6214420] http://dx.doi.org/10.1007/BF00239377

24. Roll JP, Vedel JP, Ribot E. Alteration of proprioceptive messages induced by tendon vibration in man: a microneurographic study. Exp Brain Res. 1989;76(1):213-22.

[PMID:2753103] http://dx.doi.org/10.1007/BF00253639

25. Caron O, Gelat T, Rougier P, Blanchi JP. A comparative analysis of the center of gravity and center of pressure trajectory path lengths in standing posture: an estimation of active stiffness. J Appl Biomech. 2000;16(3):234-47. [PMID:11757569]

26. Lacour M, Bernard-Demanze L, Dumitrescu M. Posture control, aging, and attention resources: models and postureanalysis methods. Neurophysiol Clin. 2008;38(6):411-21.

[PMID:19026961]

http://dx.doi.org/10.1016/j.neucli.2008.09.005

27. Paillard T, Chaubet V, Maitre J, Dumitrescu M, Borel L. Disturbance of contralateral unipedal postural control after stimulated and voluntary contractions of the ipsilateral limb. Neurosci Res. 2010;68(4):301-6. [PMID:20723569] http://dx.doi.org/10.1016/j.neures.2010.08.004

28. Bernard-Demanze L, Dumitrescu M, Jimeno P, Borel L, Lacour M. Age-related changes in posture control are differentially affected by postural and cognitive task complexity. Curr Aging Sci. 2009;2(2):139-49. [PMID:20021408] http://dx.doi.org/10.2174/1874609810902020135

29. Paillard T, Lafont C, Soulat JM, Montoya R, Costes-Salon MC, Dupui P. Short-term effects of electrical stimulation superimposed on muscular voluntary contraction in postural control in elderly women. J Strength Cond Res. 2005;19(3): 640-46. [PMID:16095419] 
30. Paillard T, Lafont C, Costes-Salon MC, Rivière D, Dupui P. Effects of brisk walking on static and dynamic balance, locomotion, body composition, and aerobic capacity in ageing healthy active men. Int J Sports Med. 2004;25(7): 539-46. [PMID:15459836] http://dx.doi.org/10.1055/s-2004-820948

31. Du Pasquier RA, Blanc Y, Sinnreich M, Landis T, Burkhard P, Vingerhoets FJ. The effect of aging on postural stability: a cross sectional and longitudinal study. Neurophysiol Clin. 2003;33(5):213-18. [PMID:14672821] http://dx.doi.org/10.1016/j.neucli.2003.09.001

32. Fujita T, Nakamura S, Ohue M, Fujii Y, Miyauchi A, Takagi $\mathrm{Y}$, Tsugeno $\mathrm{H}$. Effect of age on body sway assessed by computerized posturography. J Bone Miner Metab. 2005; 23(2):152-56. [PMID:15750694] http://dx.doi.org/10.1007/s00774-004-0554-7

33. Quoniam C, Hay L, Roll JP, Harlay F. Age effects on reflex and postural responses to propriomuscular inputs generated by tendon vibration. J Gerontol A Biol Sci Med Sci. 1995; 50(3):B155-65. [PMID:7743395]

http://dx.doi.org/10.1093/gerona/50A.3.B155

34. Pyykkö I, Jäntti P, Aalto H. Postural control in elderly subjects. Age Ageing. 1990;19(3):215-21. [PMID:2363386] http://dx.doi.org/10.1093/ageing/19.3.215

35. Thompson C, Bélanger M, Fung J. Effects of bilateral Achilles tendon vibration on postural orientation and balance during standing. Clin Neurophysiol. 2007;118(11): 2456-67. [PMID:17897877] http://dx.doi.org/10.1016/j.clinph.2007.08.013

36. Abrahámová D, Mancini M, Hlavacka F, Chiari L. The age-related changes of trunk responses to Achilles tendon vibration. Neurosci Lett. 2009;467(3):220-24. [PMID:19837131] http://dx.doi.org/10.1016/j.neulet.2009.10.041

37. Kristinsdottir EK, Fransson PA, Magnusson M. Changes in postural control in healthy elderly subjects are related to vibration sensation, vision and vestibular asymmetry. Acta Otolaryngol. 2001;121(6):700-706. [PMID:11678169] http://dx.doi.org/10.1080/00016480152583647

38. Fransson PA, Kristinsdottir EK, Hafström A, Magnusson M, Johansson R. Balance control and adaptation during vibratory perturbations in middle-aged and elderly humans. Eur J Appl Physiol. 2004;91(5-6):595-603.

[PMID:14985989] http://dx.doi.org/10.1007/s00421-003-1013-1

39. Strupp M, Arbusow V, Borges Pereira C, Dieterich M, Brandt T. Subjective straight-ahead during neck muscle vibration: effects of ageing. Neuroreport. 1999;10(15): 3191-94. [PMID:10574558] http://dx.doi.org/10.1097/00001756-199910190-00012

40. Gauchard GC, Jeandel C, Perrin PP. Physical and sporting activities improve vestibular afferent usage and balance in elderly human subjects. Gerontology. 2001;47(5):263-70.

[PMID:11490145]

http://dx.doi.org/10.1159/000052810

41. Gauchard GC, Gangloff P, Jeandel C, Perrin PP. Physical activity improves gaze and posture control in the elderly. Neurosci Res. 2003;45(4):409-17. [PMID:12657454] http://dx.doi.org/10.1016/S0168-0102(03)00008-7

42. Gauchard GC, Jeandel C, Tessier A, Perrin PP. Beneficial effect of proprioceptive physical activities on balance control in elderly human subjects. Neurosci Lett. 1999;273(2): 81-84. [PMID:10505621] http://dx.doi.org/10.1016/S0304-3940(99)00615-1

43. Paillard T, Lafont C, Pérès C, Costes-Salon MC, Soulat JM, Montoya R, Dupui P. [Is electrical stimulation with voluntary muscle contraction of physiologic interest in aging women?]. Ann Readapt Med Phys. 2005;48(1):20-28. French. [PMID:15664680] http://dx.doi.org/10.1016/j.annrmp.2004.08.005

44. Ribeiro F, Oliveira J. Aging effects on joint proprioception: the role of physical activity in proprioception preservation. Eur Rev Aging Phys Act. 2007;4:71-76. http://dx.doi.org/10.1007/s11556-007-0026-x

45. Paillard T, Noé F, Rivière T, Marion V, Montoya R, Dupui P. Postural performance and strategy in the unipedal stance of soccer players at different levels of competition. J Athl Train. 2006;41(2):172-76. [PMID:16791302]

46. Leong HT, Fu SN, Ng GY, Tsang WW. Low-level Taekwondo practitioners have better somatosensory organisation in standing balance than sedentary people. Eur J Appl Physiol. 2011;111(8):1787-93. [PMID:21221991] http://dx.doi.org/10.1007/s00421-010-1798-7

47. Golomer E, Crémieux J, Dupui P, Isableu B, Ohlmann T. Visual contribution to self-induced body sway frequencies and visual perception of male professional dancers. Neurosci Lett. 1999;267(3):189-92. [PMID:10381008] http://dx.doi.org/10.1016/S0304-3940(99)00356-0

Submitted for publication August 6, 2012. Accepted in revised form December 6, 2012.

This article and any supplementary material should be cited as follows:

Maitre J, Jully JL, Gasnier Y, Paillard T. Chronic physical activity preserves efficiency of proprioception in postural control in older women. J Rehabil Res Dev. 2013;50(6): 811-20.

http://dx.doi.org/10.1682/JRRD.2012.08.0141

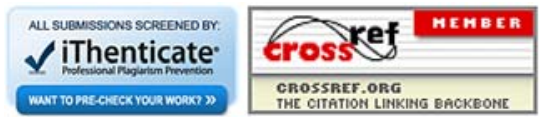


